\title{
Implantable cardioverter defibrillator therapy in hypertrophic cardiomyopathy: an updated systematic review and meta-analysis of outcomes and complications
}

\author{
Nelson Wang ${ }^{1,2}$, Ashleigh Xie ${ }^{1}$, Richard Tjahjono ${ }^{1}$, David H. Tian ${ }^{1}$, Steven Phan ${ }^{1,2}$, Tristan D. Yan ${ }^{1,2}$, \\ Pietro Bajona ${ }^{3,4}$, Kevin Phan ${ }^{1,2}$ \\ ${ }^{1}$ Collaborative Research (CORE) Group, Sydney, Australia; ${ }^{2}$ Faculty of Medicine, University of Sydney, Sydney, Australia; ${ }^{3}$ Department of \\ Cardiovascular and Thoracic Surgery, University of Texas Southwestern Medical Center, Dallas, Texas, USA; Institute of Life Sciences, Sant'Anna \\ School of Advanced Studies, Pisa, Italy \\ Correspondence to: Nelson Wang. University of Sydney, Sydney, Australia. Email: nwan5905@uni.sydney.edu.au.
}

\begin{abstract}
Background: Since the introduction of the implantable cardioverter-defibrillator (ICD) in patients with hypertrophic cardiomyopathy (HCM), the incidence of sudden cardiac death (SCD) has been significantly reduced. Given its widespread use, it is important to identify the outcomes associated with ICD use in patients with HCM. The present paper is a systematic review and meta-analysis of the rates of appropriate and inappropriate interventions, mortality, and device complications in HCM patients with an ICD.

Methods: We conducted a systematic review and meta-analysis on 27 studies reporting outcomes and complications after ICD implantation in patients with HCM. ICD interventions, device complications, and mortality were extracted for analysis.

Results: A total of 3,797 patients with HCM and ICD implantation were included (mean age, 44.5 years; $63 \%$ male), of which $83 \%$ of patients had an ICD for primary prevention of SCD. The cardiac mortality was 0.9\% (95\% CI: 0.7-1.3) per year and non-cardiac mortality was 0.8\% (95\% CI: 0.6-1.2) per year. Annualized appropriate intervention rate was $4.8 \%$ and annualized inappropriate intervention was $4.9 \%$. The annual incidence of lead malfunction, lead displacement and infection was $1.4 \%, 1.3 \%$, and $1.1 \%$, respectively.

Conclusions: ICD use in patients with HCM produces low rates of cardiac and non-cardiac mortality, and an appropriate intervention rate of $4.8 \%$ per year. However, moderate rates of inappropriate intervention and device complications warrant careful patient selection in order to optimize the risk to benefit ratio in this select group of patients.
\end{abstract}

Keywords: Implantable cardioverter-defibrillator (ICD); hypertrophic cardiomyopathy (HCM); meta-analysis

Submitted May 13, 2017. Accepted for publication Jul 03, 2017.

doi: 10.21037 /acs.2017.07.05

View this article at: http://dx.doi.org/10.21037/acs.2017.07.05

\section{Introduction}

Hypertrophic cardiomyopathy (HCM) is a cardiac disorder with an incidence of 1 in 200 and is associated with heart failure, embolism and sudden cardiac death (SCD) (1). The incidence of sudden death in HCM is low, around $0.7-1 \%$ per annum, and often young patients are affected (2). The use of implantable cardioverter-defibrillator (ICD) protects against SCD secondary to ventricular tachycardia (VT), ventricular fibrillation (VF), or bradycardia, with excellent results (3-8). A major concern with ICD therapy is the delivery of inappropriate shocks, namely in response to supraventricular tachycardia and atrial fibrillation. Furthermore, device complications including infection, lead malfunction, and lead displacements pose additional hazards, particularly in a predominantly young patient cohort who require ICD therapy for life $(4,5,7,9,10)$.

Prior observational studies have reported on the use of ICD therapy, including a meta-analysis which demonstrated 
rates of appropriate ICD interventions of $3.3 \%$ per year and inappropriate ICD interventions of $4.8 \%$ per year (6). However, a number of studies have been published since. Therefore, the goal of the present paper was to perform an updated systematic review and meta-analysis of pooled individual studies to determine the current rate of appropriate and inappropriate shocks, cardiac and non-cardiac mortality, and device complications.

\section{Methods}

\section{Literature search strategy}

The present systematic review and meta-analysis was performed in accordance to PRISMA and recommended guidelines $(11,12)$. Electronic searches were performed using Ovid Medline, PubMed, Cochrane Central Register of Controlled Trials (CCTR), Cochrane Database of Systematic Reviews (CDSR), ACP Journal Club, and Database of Abstracts of Review of Effectiveness (DARE) from their dates of inception to March 2017. To achieve the maximum sensitivity of the search strategy, we combined the terms: "hypertrophic" and "defibrillator" as either key words or MeSH terms. The reference lists of all retrieved articles were reviewed for further identification of potentially relevant studies, and assessed using the inclusion and exclusion criteria.

\section{Selection criteria}

Eligible studies for the present systematic review and meta-analysis included those in which patient cohorts underwent defibrillator therapy for HCM. Studies that did not include appropriate or inappropriate shocks, mortality, or complications as endpoints were excluded. When institutions published duplicate studies with accumulating numbers of patients or increased lengths of follow-up, only the most complete reports were included for quantitative assessment at each time interval. All publications were limited to those involving human subjects and in the English language. Abstracts, case reports, conference presentations, editorials, reviews and expert opinions were excluded.

\section{Data extraction and critical appraisal}

All data were extracted from article texts, tables and figures. Two investigators independently reviewed each retrieved article (Nelson Wang, Ashleigh Xie). Discrepancies between the two reviewers were resolved by discussion and consensus. Extracted outcome parameters were as follows: cardiac mortality, non-cardiac mortality, heart transplant, appropriate ICD intervention, inappropriate ICD intervention, and complications, including lead malfunction, infection, lead displacement, psychological complication, and total complications.

\section{Statistical analysis}

A meta-analysis of incidence rates was conducted for the available main perioperative and postoperative variables. Annualized incidence rates for appropriate, inappropriate shocks, as well as complications, were determined using the metarate function for total events per person years. Heterogeneity was evaluated using Cochran $\mathrm{Q}$ and $\mathrm{I}^{2}$ test. All analyses were performed using the meta-package for $R$ version 3.3. $P$ values $<0.05$ were considered statistically significant.

\section{Results}

A total of 1,375 articles were identified using the search strategy and 27 were included $(5,7-10)$ that met our prespecified search strategy, giving a total of 3,797 patients with HCM and ICD (13-34) (Figure 1). The mean followup of the studies ranged from 1.5 to 6.3 years. Amongst the 3,797 HCM patients with ICD (mean age, 44.5 years; $63 \%$ male), 804 (21\%) patients had obstructive HCM. The majority of the patients were given an ICD for primary prevention $(83 \%)$ compared to secondary prevention $(17 \%)$. Three of the studies used a subcutaneous ICD $(18,22,34)$. Left ventricular (LV) thickness $\geq 30 \mathrm{~mm}$, family history of SCD, non-sustained VT, syncope and abnormal blood pressure response to exercise were present in $10 \%, 26 \%, 25 \%, 7 \%$ and $22 \%$ of the patients respectively (Table $S 1)$.

The number of studies and total number of patients reporting each outcome of interest in HCM patients with an ICD are shown in Table 1. All-cause mortality occurred at a rate of $1.3 \%$ (95\% CI: $0.9-1.9)$ per year, of which cardiac mortality occurred at $0.9 \%$ (95\% CI: $0.7-1.3$ ) per year and non-cardiac mortality at $0.8 \%$ (95\% CI: $0.6-1.2)$ per year. Figure 2 shows the annual rates of appropriate ICD interventions amongst the included studies. The pooled meta-analysis of appropriate intervention rates was $4.8 \%$ (95\% CI: 3.9-5.9) per year, with significant heterogeneity 


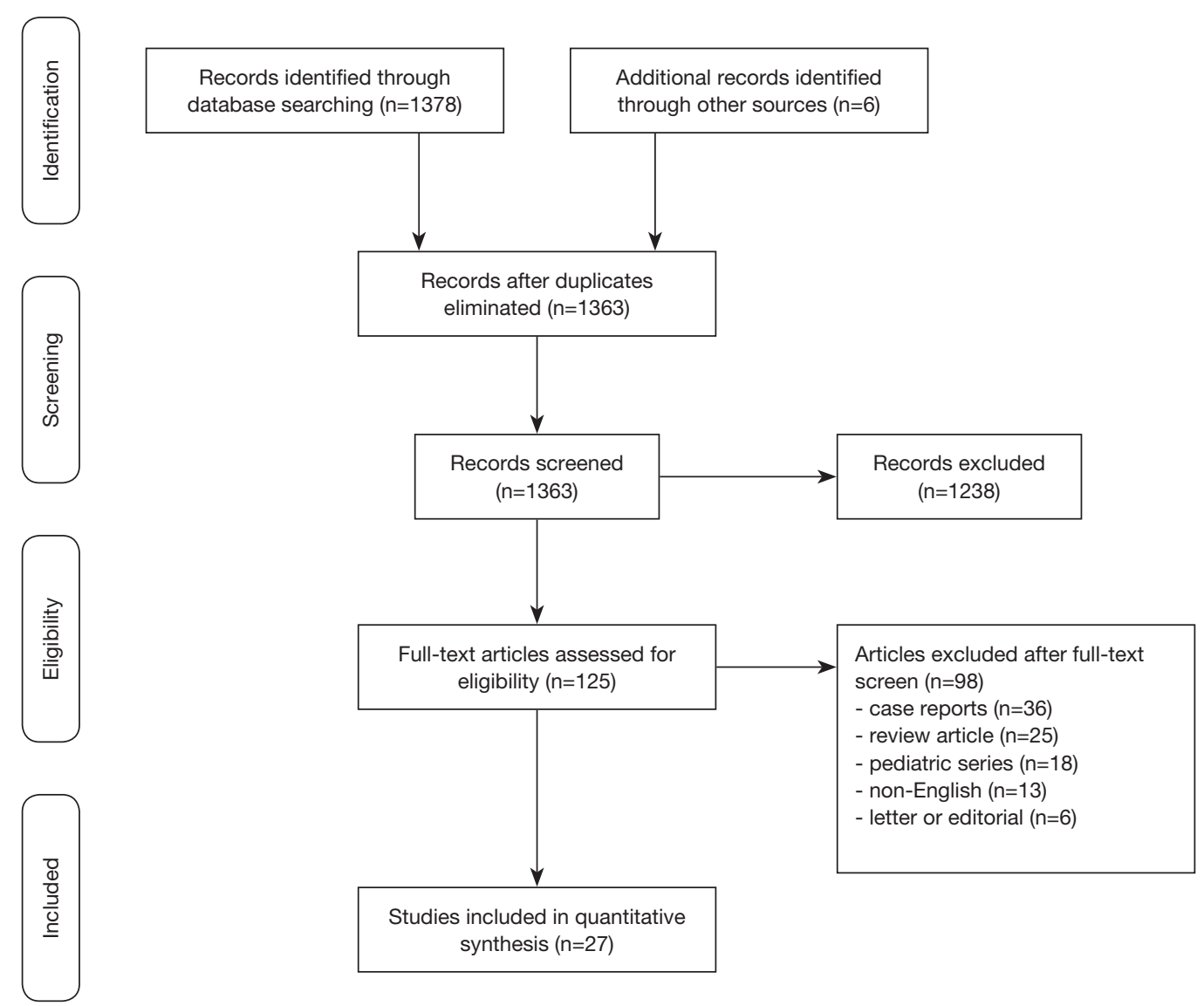

Figure 1 Study selection. Flow chart showing the results in each step of the systematic search to identify studies reporting outcomes for implantable cardioverter defibrillator therapy in hypertrophic cardiomyopathy.

between studies $\left(\mathrm{I}^{2}=84 \%\right)$. Similarly, inappropriate shocks occurred at a rate of $4.9 \%$ (95\% CI: 3.9-6.0) per year $\left(\mathrm{I}^{2}\right.$ $=75 \%$ ) (Figure 3). Among six studies $(7,8,10,25,29,33)$, heart transplant was required in $1.6 \%$ of patients per year. The annual incidence of lead malfunction and lead displacement was $1.4 \%$ (95\% CI: $0.8-2.5)$ and $1.3 \%$ (95\% CI: $0.8-2.0)$ respectively. Infection developed in $1.1 \%$ (95\% CI: $0.7-1.6)$ of patients per year (Table 1).

\section{Discussion}

The present meta-analysis shows that rates of appropriate intervention are low, with an annual incidence of $4.8 \%$ per annum. Both cardiac and non-cardiac mortality rates are also low in HCM patients with ICD $(0.9 \%$ per year and $0.8 \%$ per year, respectively), highlighting the safety and efficacy of ICDs in HCM.

The spectrum of clinical outcome in HCM is very broad, although most patients have a low annual risk of death, with a mortality rate of $1.3 \%$ and risk of sudden death of $0.7 \%$ per annum (35). SCD is the most dreaded complication of HCM and occurs in 6\% of non-referred HCM patients irrespective of age (35). Risk stratification in HCM is vital in order to assess the need for ICD. Major clinical risk factors for SCD in HCM include prior cardiac arrest, sustained VT, recurrent episodes of unexplained syncope, a firstdegree relative with SCD, LV hypertrophy ( $>30 \mathrm{~mm}$ wall thickness), an abnormal systolic blood pressure response during exercise, and non-sustained VT on ambulatory ECG monitoring (36). Although the introduction of ICD has successfully reduced rates of SCD in HCM (37), concerns about high rates of inappropriate shocks exist, and in our study, the annual incidence of inappropriate intervention was $4.9 \%$.

The historic mortality rate of greater than $5 \%$ per year for HCM has diminished with the advances in modern 


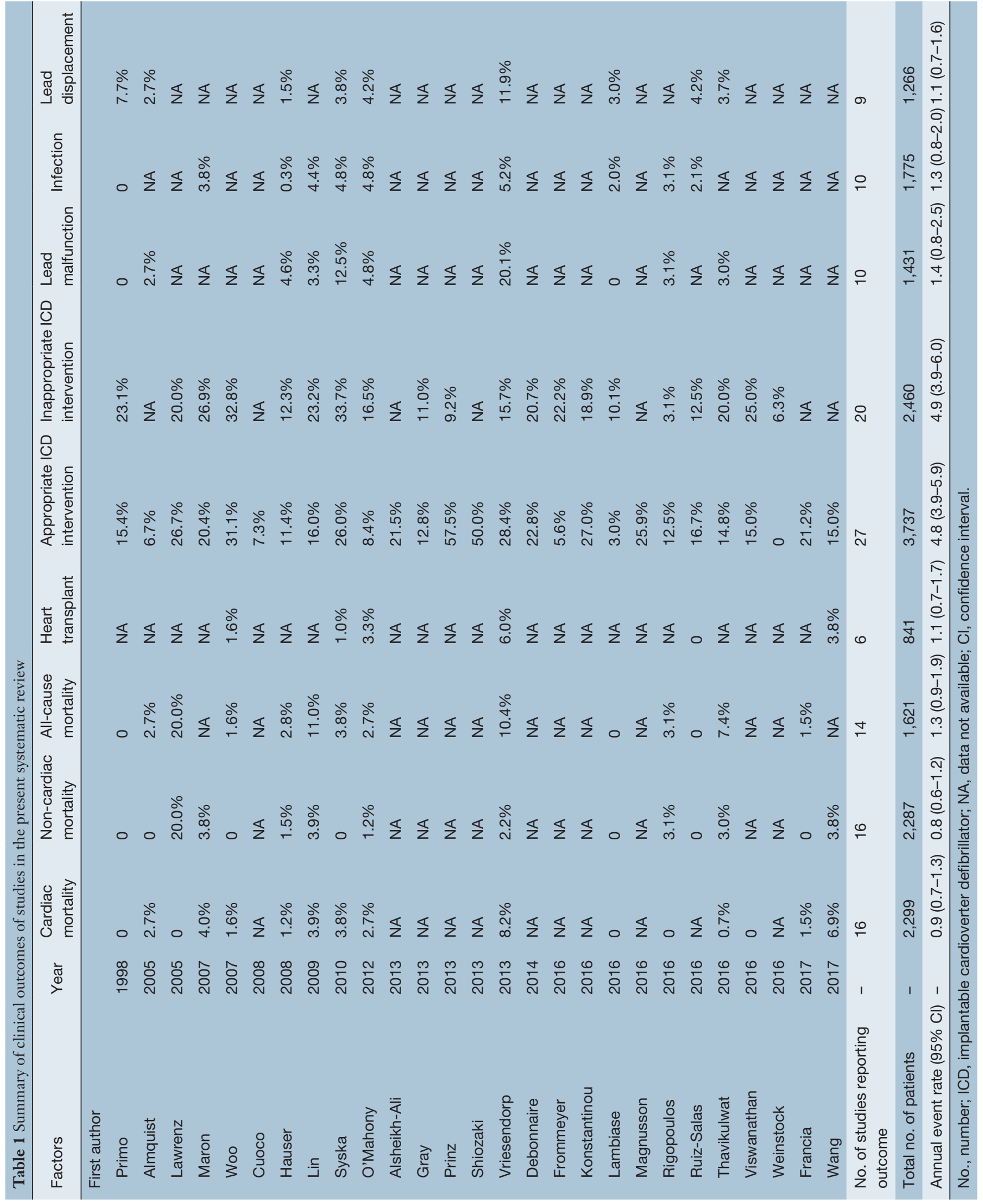




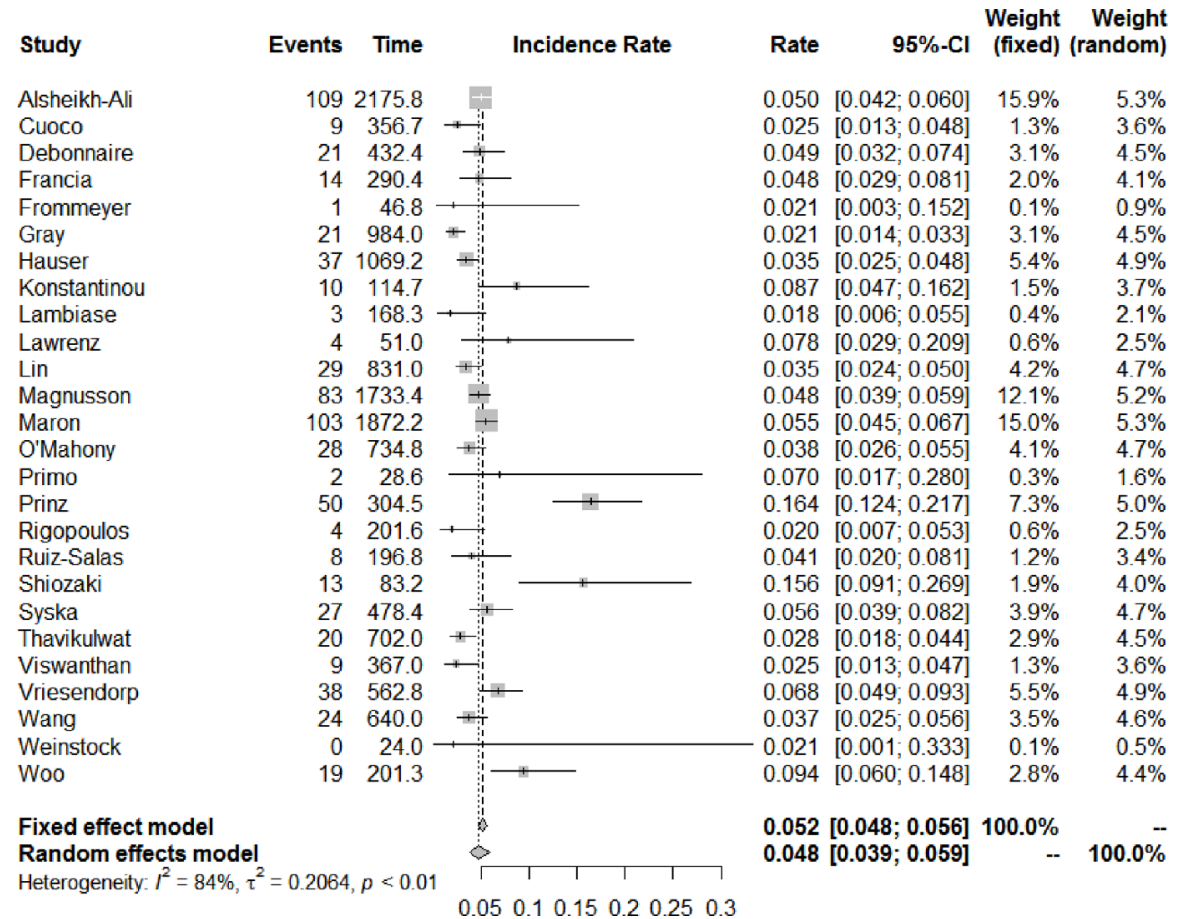

Figure 2 Annual incidence of appropriate ICD interventions. Forest plot for the annual rate of appropriate shocks with implantable cardioverter defibrillator in hypertrophic cardiomyopathy. Rate is expressed as events per year. ICD, implantable cardioverter-defibrillator; CI, confidence interval.

$\begin{array}{lrrrrrrr}\text { Study } & \text { Events } & \text { Time } & \text { Incidence Rate } & \text { Rate } & \begin{array}{r}\text { Weight } \\ \text { 95\%-Cl }\end{array} \text { (fixed) } \\ \text { (random) }\end{array}$

Figure 3 Annual incidence of inappropriate ICD interventions. Forest plot for the annual rate of inappropriate shocks with implantable cardioverter defibrillator in hypertrophic cardiomyopathy. Rate is expressed as events per year. ICD, implantable cardioverter-defibrillator; CI, confidence interval. 
medical management $(35,37)$. Primary prevention through ICDs, advanced heart failure strategies, anticoagulation for stroke prophylaxis, and septal myectomy have reduced current mortality rates to about $0.5 \%$ per year, similar to that of the general population $(35,37)$. Today, elderly patients with HCM represent around 30\% of the HCM population $(38,39)$. These patients have a more benign phenotype, with very low rates of HCM-related deaths $(39,40)$.

The pooled analysis demonstrates that inappropriate ICD intervention is common, consistent with a prior metaanalysis, which showed a similar event rate (4.8\%/year). In our study, there was significant heterogeneity in rates of inappropriate shock, likely reflecting the differences in the underlying populations, in particular rates of atrial fibrillation and supraventricular tachycardias. Patients with HCM may be more vulnerable to ICD-related complications and inappropriate ICD therapy because of their young age at implantation and increased prevalence of atrial fibrillation (9).

Reports from large multicentre registries with predominantly patients with ischemic heart disease demonstrated an early complication rate varying from $3.3 \%$ to $11 \%$ during the hospital admission for ICD implantation $(41,42)$. In the present study, the rates of infection, lead displacement and malfunction were not uncommon, with annual rates of $1.1 \%, 1.3 \%$ and $1.4 \%$, respectively. The recent advent of subcutaneous ICD represented a new alternative to traditional transvenous defibrillators. Subcutaneous ICDs pose a major advantage of less serious complications from lead failure and infection, because removal of subcutaneous ICD is a lower risk procedure compared to the removal of transvenous leads. Furthermore, the absence of a lumen in the subcutaneous leads may theoretically reduce the risk of lead failure (34). However, a subcutaneous ICD provides neither bradycardia pacing nor anti-tachycardia pacing capabilities, which limits the suitability of subcutaneous devices for certain patients who require pacing.

Given the potential complications and moderate rates of inappropriate shocks, it is important to carefully select patients who may gain the most benefit from ICD. Unlike other cardiomyopathies such as ischemic (43) or dilated (44) cardiomyopathy, use of an ICD for primary prevention of SCD in HCM is not based on randomized prospective clinical trials. The recently updated guidelines and quantitative risk estimation model (HCM Risk-SCD) have now included age, left atrial diameter and LV outflow tract gradient into the risk stratification of patients, together with traditional risk factors of family history of SCD, maximal LV wall thickness, unexplained syncope, and nonsustained VT. The evidence for the new guidelines was developed from a multicenter, retrospective, longitudinal cohort study of 3,675 patients with HCM (45). The model predicts that one SCD will be prevented every 5 years if 16 patients with a 5 -year risk of SCD that is greater than or equal to $4 \%$ are given ICD therapy (45). Validation studies have suggested that the new model is superior to traditional models based on bivariate risk factors $(29,46)$. Future studies into the role of cardiac magnetic resonance imaging may further improve the current risk models.

\section{Limitations}

The present paper has several limitations to note. The included studies were all observational and subject to significant heterogeneity, with differing population characteristics and risk profiles. There was also insufficient data to perform subgroup analyses. Secondly, the decision strategy for ICD implantation was not included in most studies. The present data does not provide time to event analyses, and crude annual event rates may not give as accurate a representation of the true incidence. There has been significant progress in the evolution of ICD implantation and the available devices and leads that have been developed. These technological advances may have contributed to some of the heterogeneity in the data. Although our results offer insight on the major clinical endpoints of HCM patients with ICD therapy, there was inadequate data for assessment of the psychological impact of these devices and their influence on quality of life.

\section{Conclusions}

Rates of appropriate ICD intervention rates are $4.8 \%$ per year, which most likely has reduced the incidence of SCD. Cardiac and non-cardiac mortality rates are low with ICD therapy in patients with HCM. However, inappropriate shocks and lead complications are not uncommon, and therefore HCM patients warrant careful risk stratification in order to accurately individualize the risk and benefits of this device.

\section{Acknowledgements}

None. 


\section{Footnote}

Conflicts of Interest: The authors have no conflicts of interest to declare.

\section{References}

1. Semsarian C, Ingles J, Maron MS, et al. New perspectives on the prevalence of hypertrophic cardiomyopathy. J Am Coll Cardiol 2015;65:1249-54.

2. Maron BJ, Olivotto I, Spirito P, et al. Epidemiology of hypertrophic cardiomyopathy-related death: Revisited in a large non-referral-based patient population. Circulation 2000;102:858-64.

3. Elliott PM, Sharma S, Varnava A, et al. Survival after cardiac arrest or sustained ventricular tachycardia in patients with hypertrophic cardiomyopathy. J Am Coll Cardiol 1999;33:1596-601.

4. Maron BJ, Shen WK, Link MS, et al. Efficacy of implantable cardioverter-defibrillators for the prevention of sudden death in patients with hypertrophic cardiomyopathy. N Engl J Med 2000;342:365-73.

5. Maron BJ, Spirito P, Shen WK, et al. Implantable cardioverter-defibrillators and prevention of sudden cardiac death in hypertrophic cardiomyopathy. JAMA 2007;298:405-12.

6. Schinkel AF, Vriesendorp PA, Sijbrands EJ, et al. Outcome and complications after implantable cardioverter defibrillator therapy in hypertrophic cardiomyopathy: Systematic review and meta-analysis. Circ Heart Fail 2012;5:552-9.

7. Syska P, Przybylski A, Chojnowska L, et al. Implantable cardioverter-defibrillator in patients with hypertrophic cardiomyopathy: Efficacy and complications of the therapy in long-term follow-up. J Cardiovasc Electrophysiol 2010;21:883-9.

8. Vriesendorp PA, Schinkel AF, Van Cleemput J, et al. Implantable cardioverter-defibrillators in hypertrophic cardiomyopathy: Patient outcomes, rate of appropriate and inappropriate interventions, and complications. Am Heart J 2013;166:496-502.

9. Lin G, Nishimura RA, Gersh BJ, et al. Device complications and inappropriate implantable cardioverter defibrillator shocks in patients with hypertrophic cardiomyopathy Heart 2009;95:709-14.

10. Woo A, Monakier D, Harris L, et al. Determinants of implantable defibrillator discharges in high-risk patients with hypertrophic cardiomyopathy. Heart 2007;93:1044-5.
11. Phan K, Tian DH, Cao C, et al. Systematic review and meta-analysis: Techniques and a guide for the academic surgeon. Ann Cardiothorac Surg 2015;4:112-22.

12. Liberati A, Altman DG, Tetzlaff J, et al. The PRISMA statement for reporting systematic reviews and metaanalyses of studies that evaluate healthcare interventions: explanation and elaboration. BMJ 2009;339:b2700.

13. Almquist AK, Montgomery JV, Haas TS, et al. Cardioverter-defibrillator implantation in high-risk patients with hypertrophic cardiomyopathy. Heart Rhythm 2005;2:814-9.

14. Alsheikh-Ali AA, Link MS, Semsarian C, et al. Ventricular tachycardia/fibrillation early after defibrillator implantation in patients with hypertrophic cardiomyopathy is explained by a high-risk subgroup of patients. Heart Rhythm 2013;10:214-8.

15. Cuoco FA, Spencer WH 3rd, Fernandes VL, et al. Implantable cardioverter-defibrillator therapy for primary prevention of sudden death after alcohol septal ablation of hypertrophic cardiomyopathy. J Am Coll Cardiol 2008;52:1718-23.

16. Debonnaire P, Thijssen J, Leong DP, et al. Global longitudinal strain and left atrial volume index improve prediction of appropriate implantable cardioverter defibrillator therapy in hypertrophic cardiomyopathy patients. Int J Cardiovasc Imaging 2014;30:549-58.

17. Francia P, Adduci C, Semprini L, et al. Prognostic implications of defibrillation threshold testing in patients with hypertrophic cardiomyopathy. J Cardiovasc Electrophysiol 2017;28:103-108.

18. Frommeyer G, Dechering DG, Zumhagen S, et al. Longterm follow-up of subcutaneous icd systems in patients with hypertrophic cardiomyopathy: A single-center experience. Clin Res Cardiol 2016;105:89-93.

19. Gray B, Ingles J, Medi C, et al. Prolongation of the qtc interval predicts appropriate implantable cardioverterdefibrillator therapies in hypertrophic cardiomyopathy. JACC Heart Fail 2013;1:149-55.

20. Hauser RG, Maron BJ, Marine JE, et al. Safety and efficacy of transvenous high-voltage implantable cardioverter-defibrillator leads in high-risk hypertrophic cardiomyopathy patients. Heart Rhythm 2008;5:1517-22.

21. Konstantinou DM, Efthimiadis GK, Vassilikos V, et al. Implantable cardioverter defibrillators for primary prevention of sudden death in hypertrophic cardiomyopathy. J Cardiovasc Med (Hagerstown) 2016;17:433-9.

22. Lambiase PD, Gold MR, Hood M, et al. Evaluation 
of subcutaneous icd early performance in hypertrophic cardiomyopathy from the pooled effortless and ide cohorts. Heart Rhythm 2016;13:1066-74.

23. Lawrenz T, Obergassel L, Lieder F, et al. Transcoronary ablation of septal hypertrophy does not alter icd intervention rates in high risk patients with hypertrophic obstructive cardiomyopathy. Pacing Clin Electrophysiol 2005;28:295-300.

24. Magnusson P, Gadler F, Liv P, et al. Risk markers and appropriate implantable defibrillator therapy in hypertrophic cardiomyopathy. Pacing Clin Electrophysiol 2016;39:291-301.

25. O'Mahony C, Lambiase PD, Quarta G, et al. The longterm survival and the risks and benefits of implantable cardioverter defibrillators in patients with hypertrophic cardiomyopathy. Heart 2012;98:116-25.

26. Primo J, Geelen P, Brugada J, et al. Hypertrophic cardiomyopathy: Role of the implantable cardioverterdefibrillator. J Am Coll Cardiol 1998;31:1081-5.

27. Prinz C, Schwarz M, Ilic I, et al. Myocardial fibrosis severity on cardiac magnetic resonance imaging predicts sustained arrhythmic events in hypertrophic cardiomyopathy. Can J Cardiol 2013;29:358-63.

28. Rigopoulos AG, Daci S, Pfeiffer B, et al. Low occurrence of ventricular arrhythmias after alcohol septal ablation in high-risk patients with hypertrophic obstructive cardiomyopathy. Clin Res Cardiol 2016;105:953-61.

29. Ruiz-Salas A, Garcia-Pinilla JM, Cabrera-Bueno F, et al. Comparison of the new risk prediction model (hcm riskscd) and classic risk factors for sudden death in patients with hypertrophic cardiomyopathy and defibrillator. Europace 2016;18:773-7.

30. Shiozaki AA, Senra T, Arteaga E, et al. Myocardial fibrosis detected by cardiac ct predicts ventricular fibrillation/ventricular tachycardia events in patients with hypertrophic cardiomyopathy. J Cardiovasc Comput Tomogr 2013;7:173-81.

31. Thavikulwat AC, Tomson TT, Knight BP, et al. Appropriate implantable defibrillator therapy in adults with hypertrophic cardiomyopathy. J Cardiovasc Electrophysiol 2016;27:953-60.

32. Viswanathan K, Suszko AM, Das M, et al. Rapid devicedetected nonsustained ventricular tachycardia in the risk stratification of hypertrophic cardiomyopathy. Pacing Clin Electrophysiol 2016;39:642-51.

33. Wang W, Lian Z, Rowin EJ, et al. Prognostic implications of nonsustained ventricular tachycardia in high-risk patients with hypertrophic cardiomyopathy. Circ Arrhythm
Electrophysiol 2017;10(3).

34. Weinstock J, Bader YH, Maron MS, et al. Subcutaneous implantable cardioverter defibrillator in patients with hypertrophic cardiomyopathy: An initial experience. J Am Heart Assoc 2016;5(2).

35. Maron BJ, Casey SA, Poliac LC, et al. Clinical course of hypertrophic cardiomyopathy in a regional united states cohort. JAMA 1999;281:650-5.

36. Gersh BJ, Maron BJ, Bonow RO, et al. 2011 accf/aha guideline for the diagnosis and treatment of hypertrophic cardiomyopathy: Executive summary: A report of the american college of cardiology foundation/american heart association task force on practice guidelines. J Thorac Cardiovasc Surg 2011;142:1303-38.

37. Maron BJ, Rowin EJ, Casey SA, et al. Hypertrophic cardiomyopathy in adulthood associated with low cardiovascular mortality with contemporary management strategies. J Am Coll Cardiol 2015;65:1915-28.

38. Maron BJ, Casey SA, Haas TS, et al. Hypertrophic cardiomyopathy with longevity to 90 years or older. Am J Cardiol 2012;109:1341-7.

39. Maron BJ, Rowin EJ, Casey SA, et al. Risk stratification and outcome of patients with hypertrophic cardiomyopathy $>=60$ years of age. Circulation 2013;127:585-93.

40. Maron BJ, Rowin EJ, Casey SA, et al. What do patients with hypertrophic cardiomyopathy die from? Am J Cardiol 2016;117:434-5.

41. Peterson PN, Daugherty SL, Wang Y, et al. Gender differences in procedure-related adverse events in patients receiving implantable cardioverter-defibrillator therapy. Circulation 2009;119:1078-84.

42. Reynolds MR, Cohen DJ, Kugelmass AD, et al. The frequency and incremental cost of major complications among medicare beneficiaries receiving implantable cardioverter-defibrillators. J Am Coll Cardiol 2006;47:2493-7.

43. Moss AJ, Zareba W, Hall WJ, et al. Prophylactic implantation of a defibrillator in patients with myocardial infarction and reduced ejection fraction. N Engl J Med 2002;346:877-83.

44. Bardy GH, Lee KL, Mark DB, et al. Amiodarone or an implantable cardioverter-defibrillator for congestive heart failure. N Engl J Med 2005;352:225-37.

45. O'Mahony C, Jichi F, Pavlou M, et al. A novel clinical risk prediction model for sudden cardiac death in hypertrophic cardiomyopathy (hcm risk-scd). Eur Heart J 2014;35:2010-20. 
46. Vriesendorp PA, Schinkel AF, Liebregts M, et al. Validation of the 2014 european society of cardiology guidelines risk prediction model for the primary prevention of sudden

Cite this article as: Wang N, Xie A, Tjahjono R, Tian DH, Phan S, Yan TD, Bajona P, Phan K. Implantable cardioverter defibrillator therapy in hypertrophic cardiomyopathy: an updated systematic review and meta-analysis of outcomes and complications. Ann Cardiothorac Surg 2017;6(4):298-306. doi: 10.21037/acs.2017.07.05 cardiac death in hypertrophic cardiomyopathy. Circ Arrhythm Electrophysiol 2015;8:829-35. 
Table S1 Characteristics of included studies of ICD therapy in patients with hypertrophic cardiomyopathy

\begin{tabular}{|c|c|c|c|c|c|c|c|c|c|c|c|c|c|c|c|}
\hline First author & Year & Sample size (n) & Study period (y) & Country & Institution & FU (years) & Age & Male (\%) & Obstructive (\%) & $\begin{array}{l}\text { ICD for primary } \\
\text { prevention of SCD (\%) }\end{array}$ & $\begin{array}{l}\text { LV thickness } \\
\geq 30 \mathrm{~mm}(\%)\end{array}$ & $\begin{array}{l}\text { Family history } \\
\text { of SCD (\%) }\end{array}$ & $\begin{array}{l}\text { Non-sustained } \\
\text { VT (\%) }\end{array}$ & Syncope (\%) & $\begin{array}{l}\text { Abnormal BP } \\
\text { response (\%) }\end{array}$ \\
\hline Primo (26) & 1998 & 13 & NA & Belgium; Spain & $\begin{array}{l}\text { Onze Lieve Vrouw Hospital; } \\
\text { University of Barcelona }\end{array}$ & 2.2 & 48 & 62 & 38 & 15 & NA & NA & NA & NA & NA \\
\hline Almquist (13) & 2005 & 75 & 1993-2004 & USA & Minneapolis Heart Institute & 3.6 & 36 & 65 & 20 & 95 & 29 & NA & NA & NA & NA \\
\hline Maron (5) & 2007 & 506 & 1986-2003 & $\begin{array}{l}\text { USA, Europe, } \\
\text { Australia }\end{array}$ & HCM ICD II Registry & 3.7 & 42 & 64 & 25 & 76 & NA & NA & NA & NA & NA \\
\hline Woo (10) & 2007 & 61 & 1996-2003 & Canada & Toronto General Hospital & 3.3 & 46 & 66 & 0 & 82 & NA & NA & NA & NA & NA \\
\hline Cuoco (15) & 2008 & 123 & NA & USA & $\begin{array}{l}\text { Medical University of South } \\
\text { Carolina; Baylor College }\end{array}$ & 2.9 & 48 & 66 & 100 & 100 & 11 & 38 & NA & 63 & 34 \\
\hline Hauser (20) & 2008 & 324 & 1992-2007 & USA & 7 Centers & 3.3 & 47 & 67 & 30 & 91 & NA & NA & NA & NA & NA \\
\hline Lin (9) & 2009 & 181 & $1988-2005$ & USA & Mayo Clinic & 4.9 & 44 & 62 & 20 & 86 & 14 & 48 & 35 & 34 & 3 \\
\hline Syska (7) & 2010 & 104 & 1996-2006 & Poland & $\begin{array}{l}\text { Warsaw Institute of } \\
\text { Cardiology }\end{array}$ & 4.6 & 36 & 45 & 46 & 75 & 23 & 81 & 35 & 69 & NA \\
\hline O’Mahony (25) & 2012 & 334 & 1992-2009 & UK & $\begin{array}{l}\text { St Georges Hospital \& Heart } \\
\text { Hospital }\end{array}$ & 2.2 & 40 & 62 & 23 & 92 & 14 & 47 & 44 & 36 & 30 \\
\hline Alsheikh-Ali (14) & 2013 & 506 & $1986-2003$ & $\begin{array}{l}\text { USA, Europe, } \\
\text { Australia }\end{array}$ & Multicenter & 4.3 & 41 & 64 & NA & 76 & NA & 41 & NA & 43 & NA \\
\hline Gray (19) & 2013 & 164 & $1997-2011$ & Australia & Royal Prince Alfred Hospital & 6 & 42 & 62 & NA & 91 & 24 & 41 & 36 & 29 & NA \\
\hline Prinz (27) & 2013 & 87 & $2000-2011$ & Germany & Ruhy University & 3.5 & 50 & 60 & 63 & 98 & 30 & 30 & 74 & 38 & 20 \\
\hline Vriesendorp (8) & 2013 & 134 & 1994-2011 & $\begin{array}{l}\text { Netherlands, } \\
\text { Belgium }\end{array}$ & $\begin{array}{l}\text { Thoraxcenter, Erasmus; } \\
\text { University Hospital Leuven }\end{array}$ & 4.2 & 44 & 66 & NA & 69 & 23 & 47 & 57 & 28 & NA \\
\hline Debonnaire (16) & 2014 & 92 & NA & Netherlands & Leiden Medical Center & 4.7 & 50 & 68 & 18 & 76 & 11 & 51 & 37 & 21 & NA \\
\hline Frommeyer (18) & 2016 & 18 & 2010-2015 & Germany & University of Muenster & 2.6 & 35 & 83 & 17 & 78 & NA & NA & NA & NA & NA \\
\hline Konstantinou (21) & 2016 & 37 & 1999-2012 & USA & Minneapolis Heart Institute & 3.1 & 49 & 76 & 27 & 100 & 38 & 38 & 59 & 38 & 35 \\
\hline Lambiase (22) & 2016 & 99 & 2009-2013 & $\begin{array}{l}\text { USA, New Zealand, } \\
\text { Netherlands, UK }\end{array}$ & EFFORTLESS \& IDE & 1.7 & 42 & 75 & NA & 88 & 8 & NA & 35 & 15 & NA \\
\hline Magnusson (24) & 2016 & 321 & 1995-2012 & Sweden & Swedish ICD Registry & 5.4 & 52 & 51 & NA & 74 & 18 & 19 & 43 & 26 & 5 \\
\hline Rigopoulos (28) & 2016 & 32 & 2009-2012 & Germany & Leopoldina Hospital & 6.3 & 50 & 53 & 17 & 97 & 17 & 50 & 54 & 63 & NA \\
\hline Ruiz-Salas (29) & 2016 & 48 & 2002-2014 & Spain & $\begin{array}{l}\text { Hospital Universitario Virgen } \\
\text { de la Victoria }\end{array}$ & 4.1 & 44 & 67 & 100 & 100 & 22 & 53 & 56 & 50 & 6 \\
\hline Thavikulwat (31) & 2016 & 135 & $2000-2013$ & USA & $\begin{array}{l}\text { Bluhm Cardiovascular } \\
\text { Institute }\end{array}$ & 5.2 & 48 & 63 & NA & 93 & NA & NA & NA & NA & NA \\
\hline Viswanathan (32) & 2016 & 60 & 1999-2012 & Canada & University Health Network & 5.1 & 44 & 73 & 23 & NA & 13 & 18 & 57 & 33 & 6 \\
\hline Weinstock (34) & 2016 & 16 & 2012-2015 & USA & Tufts Medical Center & 1.5 & 40 & NA & 50 & 81 & 14 & 28 & 29 & 29 & 8 \\
\hline Francia (17) & 2017 & 66 & 2001-2012 & Italy & St Andrea Hospital & 4.4 & 45 & 62 & 12 & 98 & 35 & 61 & 68 & 26 & NA \\
\hline Wang (33) & 2017 & 160 & 2000-2013 & USA & Tufts Medical Center & 4 & 47 & 61 & 46 & 97 & 7 & 27 & 43 & 25 & 19 \\
\hline
\end{tabular}

BP, blood pressure; FU, follow-up; ICD, implantable cardioverter-defibrillator; LV, left ventricle; NA, not available; SCD, sudden cardiac death; VT, ventricular tachycardia; HCM, hypertrophic cardiomyopathy. 